\title{
Vermiculations in painted caves: New inputs from laboratory experiments and field observations
}

\author{
Perrine Freydier (D) ${ }^{1}$, Eric Weber (D) ${ }^{2}$, Jérôme Martin (DD ${ }^{1}$, Pierre-Yves Jeannin (iD ${ }^{2}$, \\ Béatrice Guerrier (10 ${ }^{1}$, and Frédéric Doumenc (10 ${ }^{1,3^{*}}$ \\ ${ }^{1}$ Université Paris-Saclay, CNRS, FAST, 91405, Orsay, Rue André Rivière, France \\ ${ }^{2}$ Swiss Institute for Speleology and Karstology (SISKA), Serre 68, 2301 La Chaux-de-Fonds, Switzerland \\ ${ }^{3}$ Sorbonne Université, UFR 919, 4 place Jussieu, F-75252 Paris Cedex 05, France
}

\begin{abstract}
Vermiculations are aggregates of small particles commonly found on cave walls. They are a major concern for the conservation of painted caves, as they can potentially alter valuable prehistoric cave paintings. A previous rheological study of fine sediment deposits on cave walls revealed that this material can undergo a solid-to-liquid transition triggered by variations in the chemical composition of the water film on the wall. Such a transition could occur at the origin of vermiculations by allowing the sediment to flow under low mechanical stress. In this work, we provide quantitative information on the conditions leading to this transition and show the importance of the chemical composition of the water film on the cave walls. A complete understanding of the phenomenon will, however, require more field information. This includes monitoring of the evolution of vermiculations, for which we have developed a dedicated observation protocol. Based on the combination of photogrammetry and a geographic information system we were able to precisely map the walls of the Hall of Bulls in Lascaux cave from past and future photographs. To better understand the vermiculation process, pictures need to be taken regularly, and the chemical composition of the thin water film covering cave walls needs to be analyzed with a similar time step. The correlation between the evolution of vermiculations, the humidification phases of the walls, temperature changes and the chemical monitoring of the water film should shed new light on conditions triggering vermiculations.
\end{abstract}

Keywords: Vermiculations, painted caves, geographic information system, clay, rheology

Received 3 May 2021; Revised 7 September 2021; Accepted 17 September 2021

Citation: $\quad$ Freydier P., Weber E., Martin J., Jeannin P.-Y., Guerrier B., Doumenc F., 2021. Vermiculations in painted caves: New inputs from laboratory experiments and field observations. International Journal of Speleology, 50(3), 289-299. https://doi.org/10.5038/1827-806X.50.3.2390

\section{INTRODUCTION}

As defined by Bini et al. (1978), vermiculations are thin, irregular, and discontinuous deposits of incoherent materials commonly found on the walls of caves'(see Figure 1 for an example). Vermiculations can generate a wide variety of patterns, such as spot-like, dendritic or leopard-skin patterns (Parenzan, 1961; Bini et al., 1978). They are a major concern for the conservation of painted caves, as they can potentially alter valuable parietal prehistoric paintings, due to both the visual impact of the patterns and pigment migration. They have been observed in several painted caves in France: Niaux (Clottes, 1981), Font-deGaume, Rouffignac (Konik et al., 2014), and Lascaux (Hœrlé et al., 2011). In Niaux Cave, vermiculations developed after important water infiltration. J. Clottes wrote: 'The process was very fast: within a few weeks, pigments of affected paintings seemed to dissolve and disappeared entirely or partially, and blackish vermiculations formed in the whole affected area.' (Clottes, 1981). The damage was stopped by diverting the major part of the water seepage at the wall surface away from the paintings. In Lascaux Cave, new vermiculations were observed in the painted areas of the Hall of Bulls in October 2009 (Konik \& GéraudVan Solinge, 2012). A significant number of new vermiculations and shape modification of existing ones were noticed during 2010. Sparse evolutions were observed afterwards. The present study is a part of the program 'Vermiculations in Lascaux Cave' launched by the Scientific Council of Lascaux Cave after this event.

The state of knowledge about vermiculations is detailed in reviews by Bini et al. (1978) and Hœrlé (2012). The chemical and mineralogical compositions 
of vermiculations have been investigated by many authors, both in painted caves (Hœrlé et al., 2011; Konik et al., 2014) and non-painted ones (Bojar et al., 2015; Faucher \& Lauriol, 2016; Addesso et al., 2019), using a wide range of analytical techniques (X-ray diffraction, scanning electron microscope (SEM), infrared spectroscopy, thermogravimetry, etc.). These analyses show that vermiculations contain a wide variety of materials, including minerals (calcite, quartz, and clay minerals, among others) and organic matter (fungi, algae, bacteria, and organic filaments). Hœrlé et al. (2011) pointed out the similarity between the materials inside the vermiculations and those present nearby on the wall. This led them to conclude that vermiculations originate from the migration of materials lying on the cave wall. An important and fascinating fact revealed by the monitoring of painted caves is that pigments at rest for more than 10,000 years moved over centimetric distances within a time interval in the order of weeks. These 'vermiculation events' must be related to some specific conditions at the cave wall.

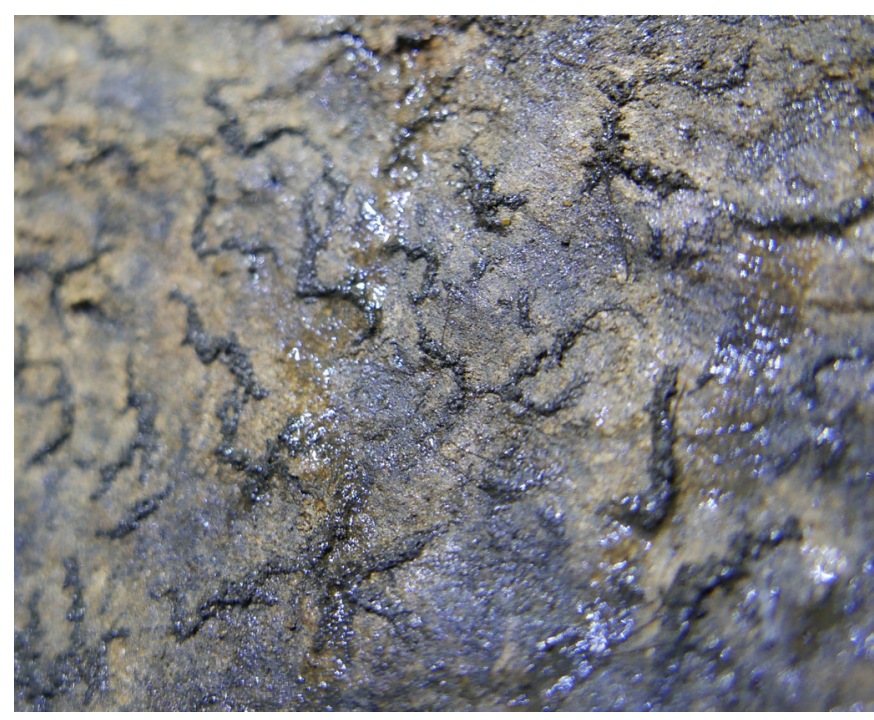

Fig. 1. Vermiculations and water film on a wall of Maillol Cave (Dordogne, France). The typical size of particle aggregates is approximately a few millimeters.

Many physical mechanisms have been proposed, most of which focus on pattern formation. Many authors have pointed out a potential connection with microbiological activity (e.g., Jones et al. (2008); Boston et al. (2009); Jurado et al. (2020)). In their review article, Bini et al. (1978) suggest that vermiculations result from the agglomeration of finegrained materials after a loss of colloidal stability. An interesting point of this theory is the major role assigned to colloidal interactions. However, the precise nature of these interactions is not specified, and this analysis does not account for the migration of particles initially at rest on cave walls.

Sedimentary particles lying on cave walls are characterized by a wide distribution of sizes. These particles include a significant number of colloidal particles (Ford \& Williams, 2007), which are smaller than $10 \mu \mathrm{m}$. Such wet granular pastes are yield stress fluids (Coussot \& Ancey, 1999), i.e., they behave as a solid when the applied mechanical stress is lower than a certain threshold (the yield stress), and they flow as a viscous fluid otherwise. This led us to postulate that specific physicochemical situations could decrease the threshold value, turning sediments from solid to fluid. This might be at the origin of a vermiculation crisis by allowing the sediment to flow under weak mechanical stress (due, for instance, to gravity, viscous friction from a thin water film, or capillarity). In a recent study (Freydier et al., 2019), we performed rheological experiments on cave sediment analogous to that of Lascaux Cave. We demonstrated that the cohesion of this material was provided by a smectite gel. Its yield stress could be varied by several orders of magnitude after soaking in aqueous solutions of different compositions.

At this point, it is worth describing the main characteristics of smectite, as it is a key element for the interpretation of the rheological experiments presented here. Readers interested in more details should refer to the specialized literature (e.g., Abend \& Lagaly, 2000; Segad et al., 2010; Hedström et al, 2016). Smectites are thin aluminosilicate platelets (typically $1 \mathrm{~nm}$ thick and 50-500 nm long), with permanent structural negatively charged faces and variable $\mathrm{pH}$-dependent charges on the edges. As the faces carry much more charge than the edges, the total charge of each particle is always negative. It is balanced by the counterion diffuse-double layer (see Fig. 2). These cations are exchangeable so that the composition of the diffuse-double layer results from thermodynamic equilibrium with the aqueous solution in which the platelets are immersed.

A concentrated smectite suspension may be in the gel or liquid phase, depending on the balance between repulsive and attractive interparticle forces. A gel is a network of particles connected through attractive forces, which balance the repulsive forces and give the material cohesion. After soaking in an aqueous solution, a smectite sample in the gel phase swells until equilibrium is reached, which is characterized by a constant water fraction, with a reduced but nonzero yield stress (i.e., the sample is still cohesive). Conversely, when interparticle repulsive forces dominate, the immersion of the sample in an aqueous solution results in the spontaneous dispersion of the particles by thermal motion.

It is well known that the smectite phase diagram strongly depends on the counterion valence (Abend $\&$ Lagaly, 2000; Hedström et al., 2016). With monovalent cations (e.g., $\mathrm{Na}^{+}$or $\mathrm{K}^{+}$), a smectite paste is in the gel phase if the salt concentration of the solution is higher than a certain value known as the critical coagulation concentration. Otherwise, it is in the liquid phase. With divalent cations (e.g., $\mathrm{Ca}^{2+}$ or $\mathrm{Mg}^{2+}$ ), a smectite paste is always in the gel phase regardless of the salt concentration (Hedström et al., 2016). The transition from Ca-smectite (always in the gel phase) to Na-smectite behavior (solid-to-liquid transition in low-mineralized water) takes place when $\mathrm{Na}^{+}$cations occupy a certain amount of the double-diffuse layer sites, typically 20\% (Karnland et al., 2011; Birgersson et al., 2011). These smectite specific features were found to fit the experimental findings on cave sediment 
cohesion (Freydier et al., 2019), which demonstrated that a sediment paste could become a liquid when successively soaked in a solution rich in monovalent cations and then in low-mineralized water.

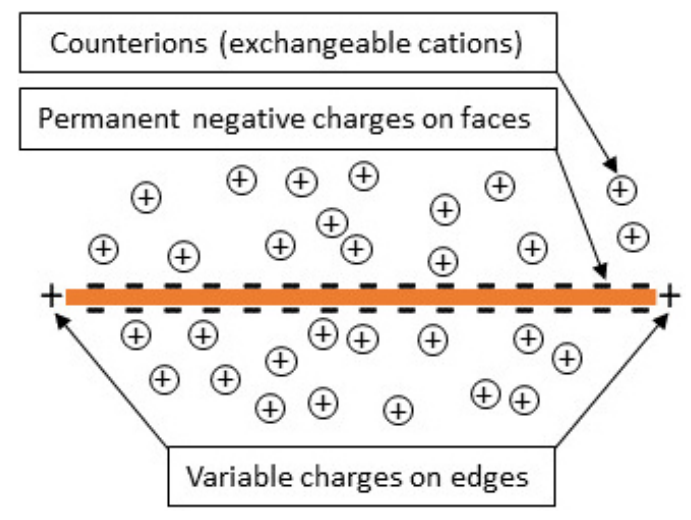

Fig. 2. Schematic view of a smectite particle.

It is therefore a key point to characterize the physicochemical conditions $(\mathrm{pH}$, salt concentration, chemical nature of ions in solution) prevailing in water films on cave walls, as they control the cohesion of the wall sediment. In the natural cave environment, the composition of flowing water resulting from quick infiltration or from seepage through porosity and fissures is well documented thanks to studies dedicated to hydrogeology and paleoclimatic reconstruction. In both types of infiltration waters, the most common ions are calcium $\left(\mathrm{Ca}^{2+}\right)$ and bicarbonate $\left(\mathrm{HCO}_{3}^{-}\right)$ provided by limestone dissolution and atmospheric $\mathrm{CO}_{2}$ (Ford \& Williams, 2007). Seven other 'major ions' are usually present at lower concentrations: the cations $\mathrm{Na}^{+}, \mathrm{K}^{+}, \mathrm{Mg}^{2+}$ and the anions $\mathrm{Cl}^{-}, \mathrm{NO}_{3}^{-}, \mathrm{SO}_{4}{ }^{2-}$, and $\mathrm{CO}_{3}{ }^{2-}$ (White, 2015). However, water in thin films at cave walls barely flows (see Fig. 1) and has therefore been rarely investigated until now. We can expect the same ions to be present, but because of the very low flow rate, some chemical species that are very diluted in flowing karst waters may be concentrated/diluted due to the evaporation/condensation that takes place in caves (de Freitas \& Schmekal, 2006; Guerrier et al., 2019). In addition, chemical equilibrium could be significantly modified by microbiological activity, resulting in the production of organic ions and $\mathrm{pH}$ modifications (Barton \& Northup, 2007).

\section{Research aim}

To improve vermiculation prevention in painted caves, the physical mechanisms at work must be elucidated, and the conditions leading to vermiculation crisis must be specified. We first present experiments on sediment rheology that are novel compared to those of Freydier (2019). We used the same protocol but further investigated the $\mathrm{NaCl}$ concentration required to turn Ca-smectite into $\mathrm{Na}$-smectite, where $\mathrm{Na}^{+}$is the monovalent cation used to study the transition from cohesive to dispersive smectite. We also investigated the time needed to achieve this transition, as well as the time required for the solid-to-liquid transition of Na-smectite soaked in deionized (DI) water.

In a second step, we try to determine whether the conditions resulting in the transition from $\mathrm{Ca}$-smectite to $\mathrm{Na}$-smectite can be achieved in the natural cave environment. For this purpose, we revisit chemical analyses performed by Lopez (2009) in Lascaux Cave in November 2004.

Coupled laboratory experiments and field observations are necessary for the understanding of the vermiculation process and the prediction of conditions leading to vermiculation formation. A precise and easy mapping tool was therefore developed to identify tiny changes in vermiculations in their natural environment and to establish correlations with other parameters, such as evaporation/condensation conditions, the presence and chemical composition of water films on the walls, evolution of calcite deposits, biological activity, position of paintings, and sensors. A dedicated field protocol was developed for this purpose, including a high-resolution geographic information system (GIS), making it possible to follow the evolution of vermiculations on the walls of the Hall of Bulls from photographic snapshots. Two challenges were faced. 1) The walls are vertical and irregular. Therefore, a local coordinate system had to be developed, and the wall relief had to be transformed into a local digital elevation model (DEM). 2) The monitoring of vermiculations is mainly conducted through photos, which are never taken at exactly the same angle. A method was thus developed to snap any picture on the local DEM. Preliminary results related to the evolution of vermiculations demonstrate the utility of this tool for cave monitoring. It makes it possible to directly compare the evolution of vermiculations with the evolution of the cave environment.

\section{MATERIAL AND METHODS}

\section{Rheological study}

The tested sediment was collected in Maillol Cave, a nonpainted cave located near Lascaux, in June 2017 (batch \#1) and in July 2018 (batch \#2). This material was selected for its similarity with the sediment of Lascaux in terms of composition and granulometry (Freydier et al., 2019). It contains high quantities of quartz and calcite and lower amounts of many other minerals, such as metallic oxides and hydroxides, igneous minerals, and various phyllosilicates (clay minerals). Calcium carbonate $\left(\mathrm{CaCO}_{3}\right)$ and organic matter represent $20 \%$ and $3 \%$ of the total dry mass, respectively. X-ray diffraction of the sediment fine fraction $(\leq 2 \mu \mathrm{m})$ revealed that smectite was the dominant clay mineral ( $80 \%$ of the fine fraction). The cation-exchanged capacity (CEC), which represents the total amount of exchangeable electric charges per unit of sediment dry mass, was similar for batch $\# 1$ and batch \#2: $20 \mathrm{cmol}+/ \mathrm{kg}$ and $16 \mathrm{cmol}+/ \mathrm{kg}$, respectively.

Yield stress measurements were performed to characterize the sediment cohesion under various conditions. The experimental methods outlined in this section were described in detail by Freydier et al. (2019). A first rheological characterization of the sediment paste was performed following the protocol depicted in Figure 3a. Samples with different solid mass fractions were prepared by adding DI water (electrical resistivity: $18 \mathrm{M} \Omega \cdot \mathrm{cm}$ ) to the dried sediment 
and mixing it manually with a spatula (the solid mass fraction, denoted as $\mathrm{W}_{\mathrm{s}}$, is the ratio of the dry mass to the total mass). The yield stress $\tau_{c}$ was measured at $20^{\circ} \mathrm{C}$ using an Anton Paar Physica MCR 501 rheometer equipped with a $25 \mathrm{~mm}$ parallel-plate geometry. More specifically, the shear rate was recorded as a function of time for an imposed stress. The stress was gradually increased step by step until the solid-toliquid transition was detected. This protocol provides a first relation between the yield stress $\tau_{c}$ and the solid fraction $\mathrm{W}_{\mathrm{s}}$, which characterizes the sediment when mixed with DI water.

In a cave, the amount of water as well as the nature and concentration of ions in the sediment layer result from exchanges with the water film lying on the wall, whose composition is expected to vary over time (seasonal variations of percolated water composition, ion dilution or concentration by condensation or evaporation, consequences of microbiological activity). Measuring the yield stress of sediment deposits after soaking in solutions of various compositions allows us to mimic situations potentially encountered in caves. This protocol is depicted in Figure 3b. Before each soaking experiment, the material was prepared by mixing dried sediment and DI water. The initial material state was characterized by measuring the solid mass fraction $\mathrm{W}_{\mathrm{s}}$ and the yield stress $\tau_{\mathrm{c}}$ (protocol of Fig. 3a). A microscope glass slide was then coated with a 1-mm-thick layer of material (sample volume: $2 \mathrm{~cm}^{3}$ ). This sample was immediately soaked in a volume of solution fixed at $20 \mathrm{~cm}^{3}$. The cup containing the sample and the soaking solution is then placed in a controlled atmosphere box swept by an air flow saturated with water vapor to avoid evaporation (in the present work, the partial pressure of $\mathrm{CO}_{2}$ was fixed to $0.035 \% \pm 0.005 \%$ of the atmospheric pressure, but values up to $10 \%$ could be imposed; see Freydier et al. (2019)). After a certain lapse of time that could be varied (called the soaking time subsequently), the sample was removed from the cup. The solid fraction and the yield stress were measured to determine the effect of soaking on sediment cohesion. Multiple soakings were done one after another to mimic contact of sediment with water of different origins (e.g., an intake of percolated water followed by a condensation event). (a)

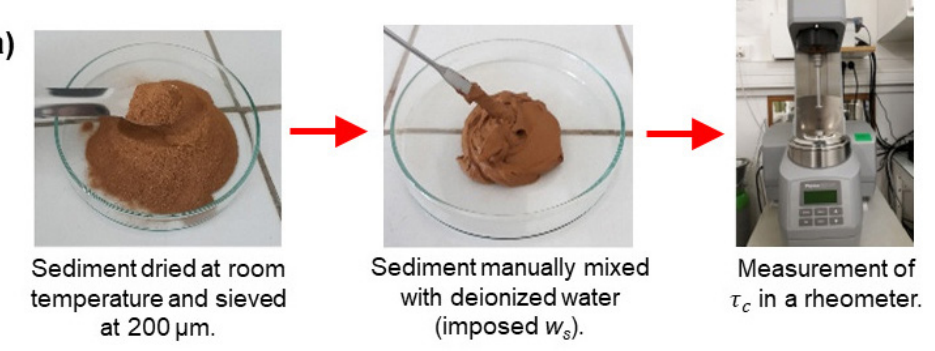

(b)

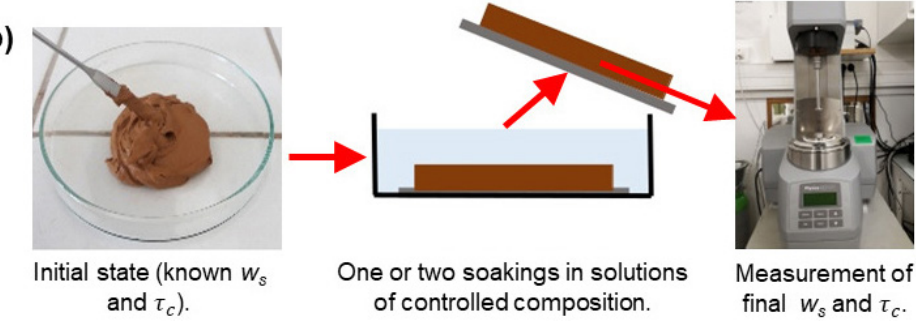

Fig. 3. Experimental procedures for rheological experiments. a) Imposed solid mass fraction $\mathrm{W}_{\mathrm{s}}$ for sediment characterization. b) Soaking experiments.

\section{Development of a GIS for the Hall of Bulls of Lascaux Cave}

Based on existing LIDAR measurements of cave walls, a local georeferencing system was defined considering the best projection plan for each vermiculated section of cave walls. This was searched visually using the existing $3 \mathrm{D}$ LIDAR model made by Perazio Engineering. A $5 \mathrm{~cm}$ resolution model of both walls was thus projected into a unique local coordinate system and placed in Q-GIS software to give an outlook. Vermiculated areas of approximately $1 \mathrm{~m}^{2}$ were mapped with a much higher resolution (approximately $0.1 \mathrm{~mm}$ ) using photogrammetry, which required several high-resolution pictures (Nikon D-800, 7360 x 4912 pixels on a 35.9 x 24 mm sensor) from different angles. A 3D relief was thus produced for each area using Photoscan software. From the key features of the wall areas (reference points), the $3 \mathrm{D}$ reliefs could be georeferenced and integrated into the Q-GIS project. Orthoimages with a perpendicular projection angle could then be produced and integrated. Assuming that the reference points of the wall do not change in time, any single picture of the wall could now be integrated and directly compared with other images. This made it possible to include old pictures, even those from the 1980s. For comparison, vermiculations at a given reference time (e.g., before the 2009-2010 crisis) were digitized (outlined). Various techniques were tested for this work, and the best results were obtained with manual digitization by a trained person. Automatic treatment failed mainly because the lighting and the aspect of cave walls change too much from one picture to another. Figure 4 shows an example of the evolution of vermiculations as obtained from the GIS tool. This method is now efficient, as each vermiculated area can be mapped very rapidly, just by taking a few pictures. The formation of new vermiculations, shape modification, and the disappearance of existing vermiculations can thus be easily detected. 

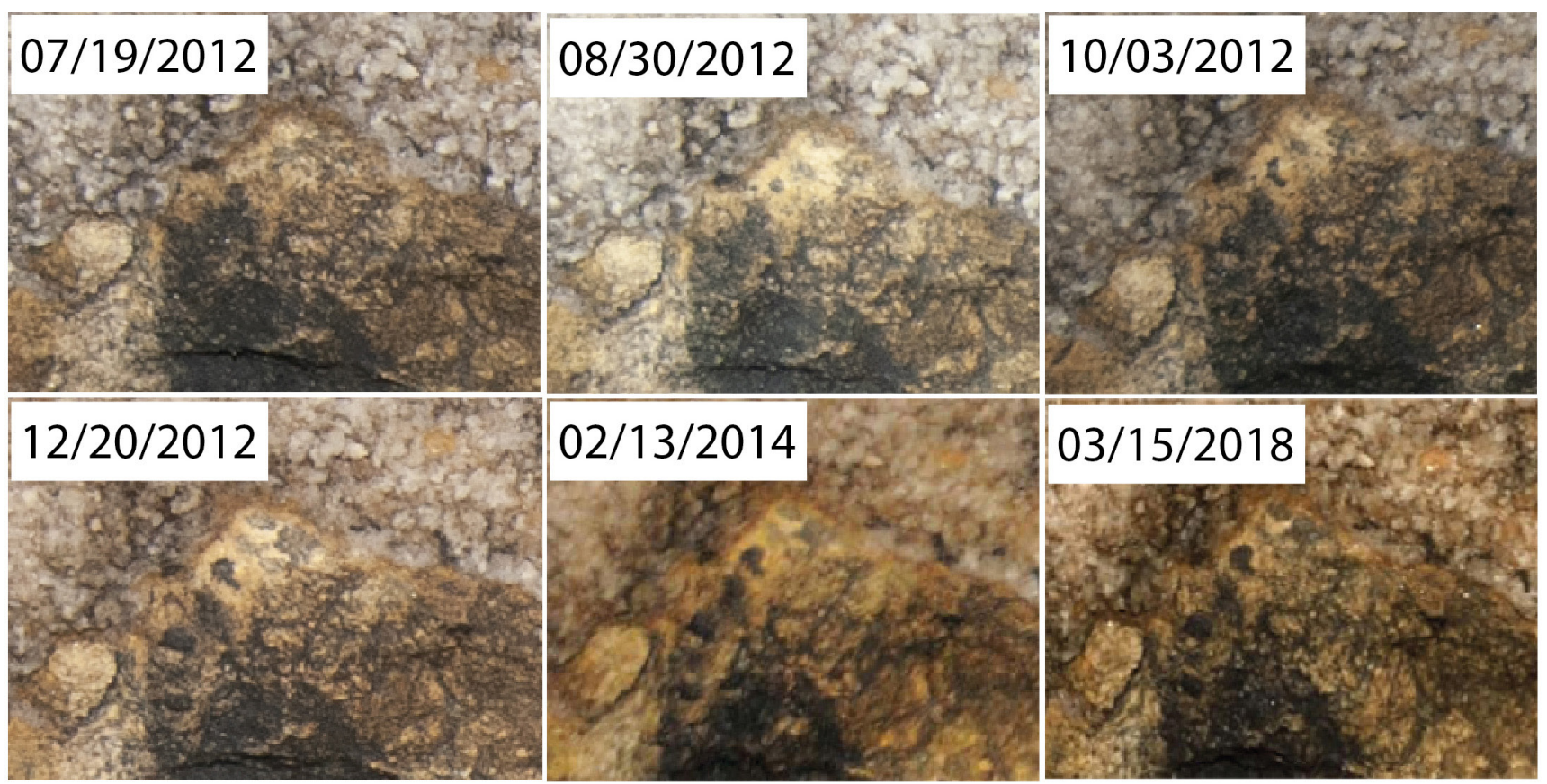

Fig. 4. Example of vermiculation evolution in six images of the same spot at the top of the STG19 area, located between the legs of a horse, on the left wall of the Hall of Bulls. Size of the pictures: $6 \times 4 \mathrm{~cm}$.

\section{RHEOLOGICAL CHARACTERIZATION OF CAVE SEDIMENTS}

As outlined in the introduction, the rheology of smectite is very sensitive to the counterion valence. When the sediment was collected in Maillol Cave, the dominant counterion in smectite was $\mathrm{Ca}^{2+}$ (Freydier et al., 2019). To test the influence of a sudden and temporary increase in the concentration of monovalent ions in the water in contact with the sediment, sediment samples were soaked first in $\mathrm{NaCl}$ aqueous solutions of varying concentrations (from 0 to $30 \mathrm{mmol} / \mathrm{L}$ ) and then in DI water. The results are displayed in Figure 5a. The initial sediment state before soaking is indicated by a gray star $\left(\tau_{c}=3,000\right.$ $\mathrm{Pa}$ and $\left.\mathrm{W}_{\mathrm{s}}=67 \%\right)$. Circles and crosses were obtained after one or two soakings, respectively (protocol of Fig. 3b). An arrow drawn under a symbol indicates that the yield stress was too low to be measured and only a higher bound could be obtained.

In the first step, we analyzed the influence of the $\mathrm{NaCl}$ concentration for a fixed soaking time. The open circles in Figure $5 \mathrm{a}$ represent the yield stress after 1 day in solutions with different $\mathrm{NaCl}$ concentrations. Moderate decreases in $\mathrm{W}_{\mathrm{s}}$ and $\tau_{\mathrm{c}}$ were observed, with negligible effect of $\mathrm{NaCl}$ concentration (notice that a significant effect of $\mathrm{NaCl}$ concentration was obtained with longer soaking times (Freydier et al., 2019)).

We turn now to the second soaking in DI water (crosses in Fig. 5a). It appears that the effect of DI water strongly depended on the $\mathrm{NaCl}$ concentration that was imposed during the first soaking. The mass fraction $\mathrm{W}_{\mathrm{s}}$ and the yield stress $\tau_{\mathrm{c}}$ were nearly unchanged for $\mathrm{NaCl}$ concentrations below $3 \mathrm{mmol} / \mathrm{L}$, but a considerable drop in both $\mathrm{W}_{\mathrm{s}}$ and $\tau_{\mathrm{c}}$ occurred at $\mathrm{NaCl}$ concentrations above $10 \mathrm{mmol} / \mathrm{L}$. For the largest $\mathrm{NaCl}$ concentration in the first soaking solution (30 $\mathrm{mmol} / \mathrm{L}$ ), only a higher bound of the yield stress could be identified after the second soaking (this value could thus be zero).

Preliminarily, the fact that no yield stress drop was observed after a single soaking in DI water confirmed that, when the sediment was collected in Maillol Cave, the dominant counterion in smectite was divalent, most likely calcium $\left(\mathrm{Ca}^{2+}\right)$.

When $\mathrm{Na}^{+}$cations are present in the solution, they are substituted for $\mathrm{Ca}^{2+}$ counterions in the diffusedouble layer. This process contributes to enriching the diffuse double layer in $\mathrm{Na}^{+}$ions and the solution in $\mathrm{Ca}^{2+}$. Ion exchange stops when thermodynamic equilibrium is reached. The greater the initial $\mathrm{Na}^{+}$ concentration in the solution, the greater the number of sites occupied by $\mathrm{Na}^{+}$in the diffuse double layer at the end of the first soaking.

No collapse of the yield stress was observed after this first soaking because (i) at low $\mathrm{NaCl}$ concentrations, divalent $\mathrm{Ca}^{2+}$ counterions still dominated in the diffuse-double layer, and they prevented the dispersion of smectite particles and (ii) at high $\mathrm{NaCl}$ concentrations, the number of substitutions of $\mathrm{Ca}^{2+}$ by $\mathrm{Na}^{+}$in the diffuse double layer was sufficient to turn the initial Ca-smectite into Na-smectite. However, the $\mathrm{NaCl}$ concentration in the solution was high enough to maintain Na-smectite in the gel phase. This was no longer the case after the second soaking in DI water. Interactions between smectite particles turned to repulsion, they were dispersed by thermal motion, and the yield stress of the sediment dramatically dropped because it lost its binder.

Interestingly, the effect of spontaneous dispersion of small particles is clearly visible in Figure 5b. This picture was taken at the end of the second soaking, just before sample removal for yield stress measurements. The samples are, from left to right, samples first soaked in 0 (DI water), 1, 3, 10, and $30 \mathrm{mmol} / \mathrm{L} \mathrm{NaCl}$. Spontaneous particle dispersion is clearly visible from $3 \mathrm{mmol} / \mathrm{L} \mathrm{NaCl}$. It increases with the $\mathrm{NaCl}$ concentration. This strong correlation 
between yield stress collapse and particle dispersion was observed in all our experiments. Aside from providing interesting information about the physical mechanisms at play, this observation suggests an easy test to detect physicochemical conditions leading to the dispersion of the colloidal particles (smectite particles in our case) that ensure sediment cohesion.
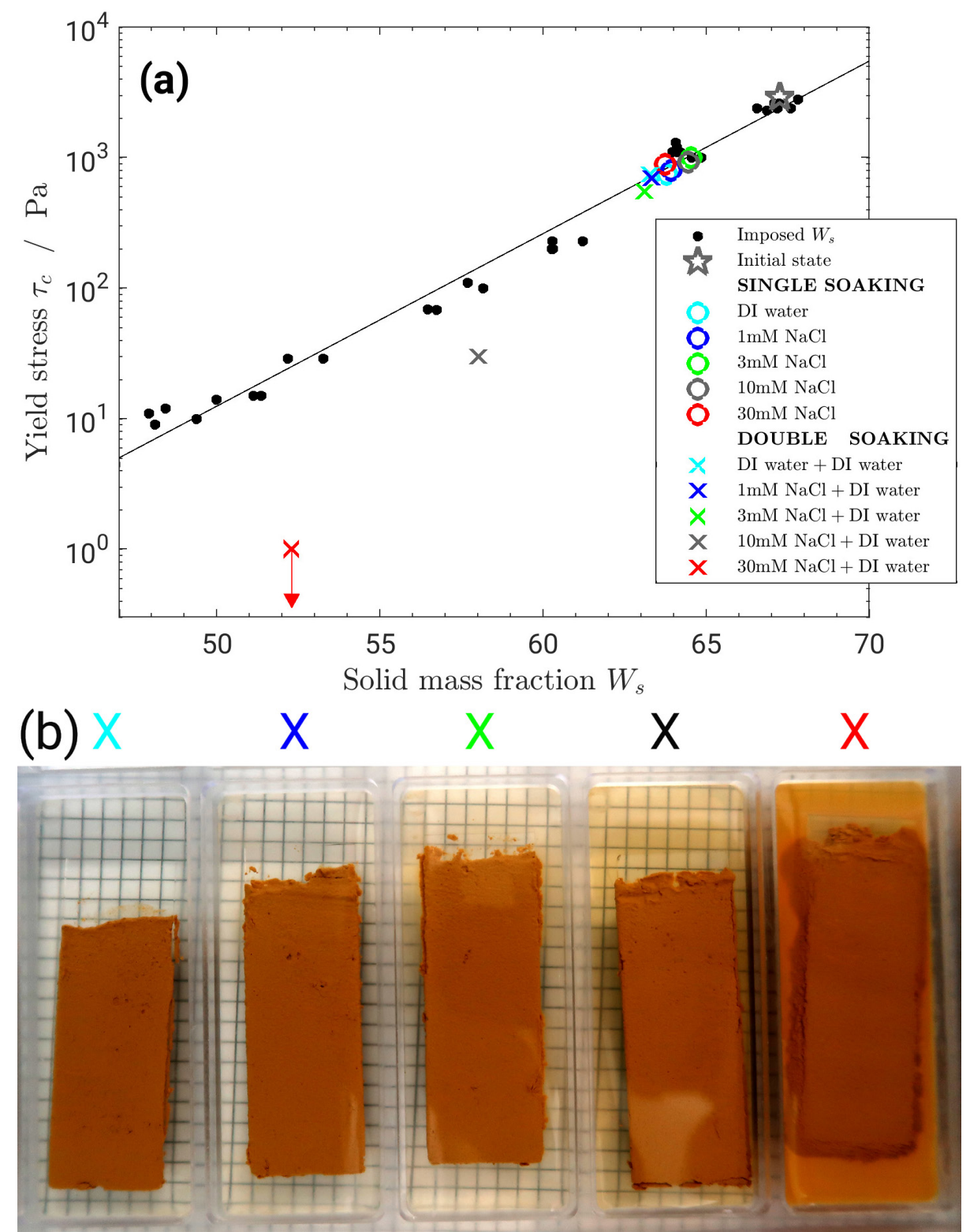

Fig. 5. Effect of $\mathrm{NaCl}$ concentration in the first soaking bath $(0,1,3,10$ and $30 \mathrm{mmol} / \mathrm{L})$. a) Yield stress as a function of the solid mass fraction after a single soaking (circles) or double soaking (crosses). The colors refer to the $\mathrm{NaCl}$ concentration during the first or single soaking, see the legend (the arrow below the red cross means that only a higher bound of the yield stress could be determined). b) Sediment samples at the end of double soaking ( $\mathrm{NaCl}$ concentration during the first soaking increasing from left to right, the color of crosses at the top of the picture corresponds to the legend in Figure 5a). Soaking time: 24 hours in all cases. Sediment batch \#2.

For a given concentration of $\mathrm{NaCl}$ in the solution, we then investigated the time required for $\mathrm{Ca}^{2+}$ to $\mathrm{Na}^{+}$substitutions during the first soaking. Figure $6 \mathrm{a}$ displays the yield stress $\tau_{c}$ as a function of the solid fraction $\mathrm{W}_{\mathrm{s}}$ (i) after the first soaking of varying duration (from an hour to 63 days) in $27 \mathrm{mmol} / \mathrm{L} \mathrm{NaCl}$ aqueous solution (circles) and (ii) after the second soaking for a day in DI water (crosses). As expected, decreases in $\tau_{c}$ and $W_{s}$ were observed after the first soaking and were more pronounced as the soaking time increased. However, the most striking effect was observed after the second soaking. One hour in $\mathrm{NaCl}$ was enough to induce a significant drop in $\tau_{c}$ after the second soaking in DI water, and cohesion was completely lost for first soaking times greater than or equal to 2 hours. We conclude that the time required for counterion substitutions is in the order of an hour. This is much less than the values reported by Karnland et al. (2011), in the order of 10 days for 5-mm-high samples of Casmectite clay (CEC close to $100 \mathrm{cmol}+\cdot \mathrm{kg}^{-1}$, solid mass fractions in the range from $60 \%$ to $78 \%$ ), exchanging cations with a $10 \mathrm{mmol} / \mathrm{L} \mathrm{NaCl}$ solution through semipermeable membranes. A lower thickness (1 $\mathrm{mm}$ ), a lower CEC (approximately $20 \mathrm{cmol}+\cdot \mathrm{kg}^{-1}$ ), and the absence of membranes might explain the lower characteristic times in our experiments.

The time required for smectite dispersion during the second soaking in DI water was also investigated 
(Fig. 6b). The samples were first soaked in $27 \mathrm{mmol} / \mathrm{L}$ $\mathrm{NaCl}$ solution for 24 hours and then in DI water for 20 minutes to 24 hours. We observed that 20 minutes in DI water was enough to trigger an important drop in the yield stress (from 1,000 $\mathrm{Pa}$ to approximately $100 \mathrm{~Pa})$, as shown in Figure 6b. For times greater than or equal to two hours, the sample lost its cohesion, and it was hardly discernible if there was

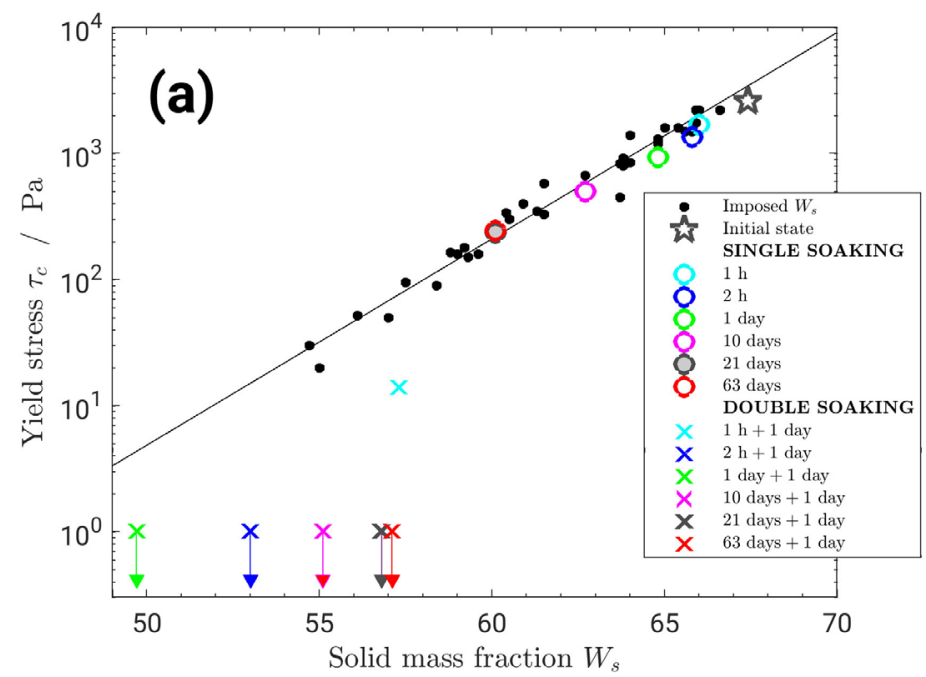

still a yield stress.

In conclusion, the times required for counterion substitutions and smectite dispersion were both surprisingly short, in the order of hours. These phenomena can thus be considered instantaneous, since they are certainly much faster than any other events that take place in a cave, such as water composition changes or flow rate variations.

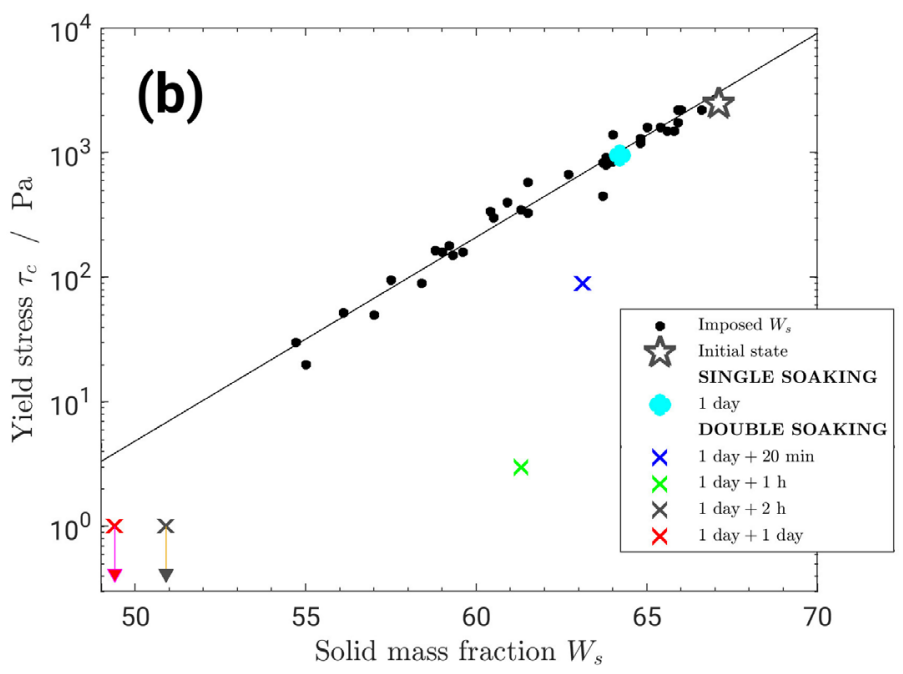

Fig. 6. Yield stress as a function of the solid mass fraction for different soaking times. a) First or single soaking in NaCl solution for various durations and second soaking in DI water for 24 hours. b) First or single soaking in the NaCl solution for 24 hours and second soaking in DI water for variable durations. The concentration of all $\mathrm{NaCl}$ solutions was $27 \mathrm{mmol} / \mathrm{L}$. Sediment batch \#1.

\section{Chemical composition of water films in Lascaux Cave}

The ratio between the concentrations in monovalent and multivalent cations in water films on cave walls must be assessed because it strongly affects the cohesion of sediments. $\mathrm{Ca}^{2+}$ is expected to be the most common cation in a karstic environment, where limestone rock dominates. However, the concentration in $\mathrm{Ca}^{2+}$ is limited by the low solubility of $\mathrm{CaCO}_{3}$. For instance, if water evaporates, it could happen that the concentration in monovalent cations $\mathrm{Na}^{+}$and $\mathrm{K}^{+}$ increases while the concentration in $\mathrm{Ca}^{2+}$ remains constant because it precipitates with carbonate ions $\left(\mathrm{CO}_{3}{ }^{2-}\right)$. Moreover, the solubility of $\mathrm{CaCO}_{3}$ depends on $\mathrm{CO}_{2}$ partial pressure in the cave atmosphere, which governs the concentration of carbonic acid in the liquid phase (Plummer \& Wigley, 1976). It can also be increased or decreased if other acids or bases are present. For these reasons, the relative evolution of monovalent cations (e.g., $\mathrm{Na}^{+}$or $\mathrm{K}^{+}$) and divalent $\mathrm{Ca}^{2+}$ may be difficult to assess. In the literature, very few studies have explored the chemical composition of thin water films in caves. One main reason is that sampling of a thin water film is very challenging. Lopez (2009) succeeded in collecting water samples from films and droplets at three locations in Lascaux Cave after a condensation event in November 2004. He then measured the concentrations of major ions in these samples (see Table 1, where Lopez's data have been converted from mass concentrations to molar concentrations). The author indicates that ammonium ions $\left(\mathrm{NH}_{4}^{+}\right)$and some organic compounds have been detected on chromatograms but could not be identified or quantified because of insufficient sample volumes. The alkalinity, which is affected by bicarbonate $\left(\mathrm{HCO}_{3}{ }^{-}\right)$, carbonate $\left(\mathrm{CO}_{3}{ }^{2-}\right)$ and potentially weak organic acids (Reddy et al., 1990), was not measured, likely for the same reason.

The first striking characteristic indicated by the data in Table 1 is strong mineralization, far above the concentrations expected in karst aquifers (for instance, the $\mathrm{Cl}^{-}$concentration in $\mathrm{A}$ is approximately 100 $\mathrm{mmol} / \mathrm{L}$, which corresponds to a mass concentration of approximately $4 \mathrm{~g} / \mathrm{L}$ ). As pointed out in the rheology section, the cation valence is of primary importance for sediment rheology. Among the analyzed cations, divalent $\mathrm{Ca}^{2+}$ was dominant in locations $\mathrm{A}$ and $\mathrm{B}$, but the $\mathrm{K}^{+}$molarity was nearly twice that of $\mathrm{Ca}^{2+}$ in location $\mathrm{C}$. Moreover, the principle of electroneutrality of the solution was not verified by the measurements. Indeed, the electrical balance of analyzed ions showed an important lack of positive charges in locations A and $\mathrm{B}$, indicating the presence of many unmeasured cations. The electrical balance of the analyzed ions was close to zero in C. However, we must keep in mind that the alkalinity was not measured. As a significant concentration of $\mathrm{HCO}_{3}^{-}$is expected, unmeasured cations should also be present at location $\mathrm{C}$.

The interpretation of these data is complicated by the strong degree of anthropization of Lascaux Cave and by the large quantities of biocides that have been applied on walls in the past (Alonso et al., 2019). Anyways, our laboratory results show that the nature of cations in water films might trigger the vermiculation process through sediment rheology. The chemical composition of water films and droplets in Lascaux Cave should therefore be monitored, including by identifying and quantifying the concentrations of organic ions. This 
requires a preliminary study to improve sampling techniques and to define appropriate analysis methods. Comparisons with a natural cave (e.g., Maillol Cave located near Lascaux) should be useful to distinguish between effects of anthropic or natural origin.

Table 1. Molar concentrations $(\mathrm{mmol} / \mathrm{L})$ in water samples from Lascaux Cave in November 2004 obtained by Lopez (2009). The samples were collected in water films and droplets on the bench of the Hall of Bulls (column A), on inclined planes of the Axial Gallery (column B), and on the walls of the Hall of Bulls (column C). The concentrations were determined by liquid chromatography.

\begin{tabular}{|c|c|c|c|c|}
\hline & & $\mathbf{A}$ & B & $\mathbf{C}$ \\
\hline \multicolumn{2}{|c|}{$\mathrm{K}^{+}$} & 0.38 & 0.39 & 8.11 \\
\hline \multicolumn{2}{|c|}{$\mathrm{Na}^{+}$} & 0.15 & 0.13 & 0.96 \\
\hline \multicolumn{2}{|c|}{$\mathrm{Ca}^{2+}$} & 5.26 & 8.13 & 3.68 \\
\hline \multicolumn{2}{|c|}{$\mathrm{Mg}^{2+}$} & 0.21 & 0.20 & 0.35 \\
\hline \multicolumn{2}{|c|}{$\mathrm{Cl}^{-}$} & $110-140$ & 19.7 & 16.2 \\
\hline \multicolumn{2}{|c|}{$\mathrm{NO}_{3}^{-}$} & 0 & 12.5 & 0.47 \\
\hline \multicolumn{2}{|c|}{$\mathrm{SO}_{4}{ }^{2-}$} & 0.09 & 2.02 & 0.30 \\
\hline \multirow{3}{*}{$\begin{array}{l}\text { Electrical } \\
\text { charges } \\
\text { meq/L }\end{array}$} & Positive & 11.5 & 17.2 & 17.1 \\
\hline & Negative & $110-140$ & 36.2 & 17.3 \\
\hline & Balance & $\sim-110$ & -19 & -0.2 \\
\hline
\end{tabular}

\section{MONITORING THE EVOLUTION OF VERMICULATIONS IN LASCAUX THROUGH A GIS}

The observation protocol described in the methodology section was applied to describe the walls of the Hall of Bulls in Lascaux Cave. The vermiculation map shown in Figure 7 was obtained after digitization. This figure displays all the vermiculations observed in the STG9 area between January 2, 1980 and March 1, 2018 (the dates of the first and last images processed within the context of the present work). The STG9 area is located along the back of the unicorn on the left wall of the Hall of Bulls (see the inset). This area was chosen because of its large vermiculation density. It is not representative of the general state of Lascaux Cave.

Thanks to existing pictures, information about the evolution of vermiculations in the STG9 area could be assessed and is summarized in Table 2. Three types of events were recorded: formation of new vermiculations, shape modification of existing vermiculations and disappearance of existing vermiculations. A total of 714 new vermiculations were identified over the whole time period. Only 33 vermiculations, accounting for $4.6 \%$ of the total number, were present in this area in 1980. Determining the exact date of their formation is impossible because the resolution of older pictures is too low. A much larger number of vermiculations was observed in 2009. Although it was not possible to obtain enough exploitable pictures to extract the details of the evolution from 1980 to 2009 , we know from visual inspections of curators that a considerable proportion of these vermiculations were formed during the crisis of 2009-2010. The number of new vermiculations during these two years was 611 , accounting for $85.6 \%$ of the total number.

A significant slowdown was observed during the years following this crisis. However, importantly, vermiculation activity did not cease. An average of approximately 9 new vermiculations per year developed between 2010 and 2018, which accounts for $9.8 \%$ of the total.

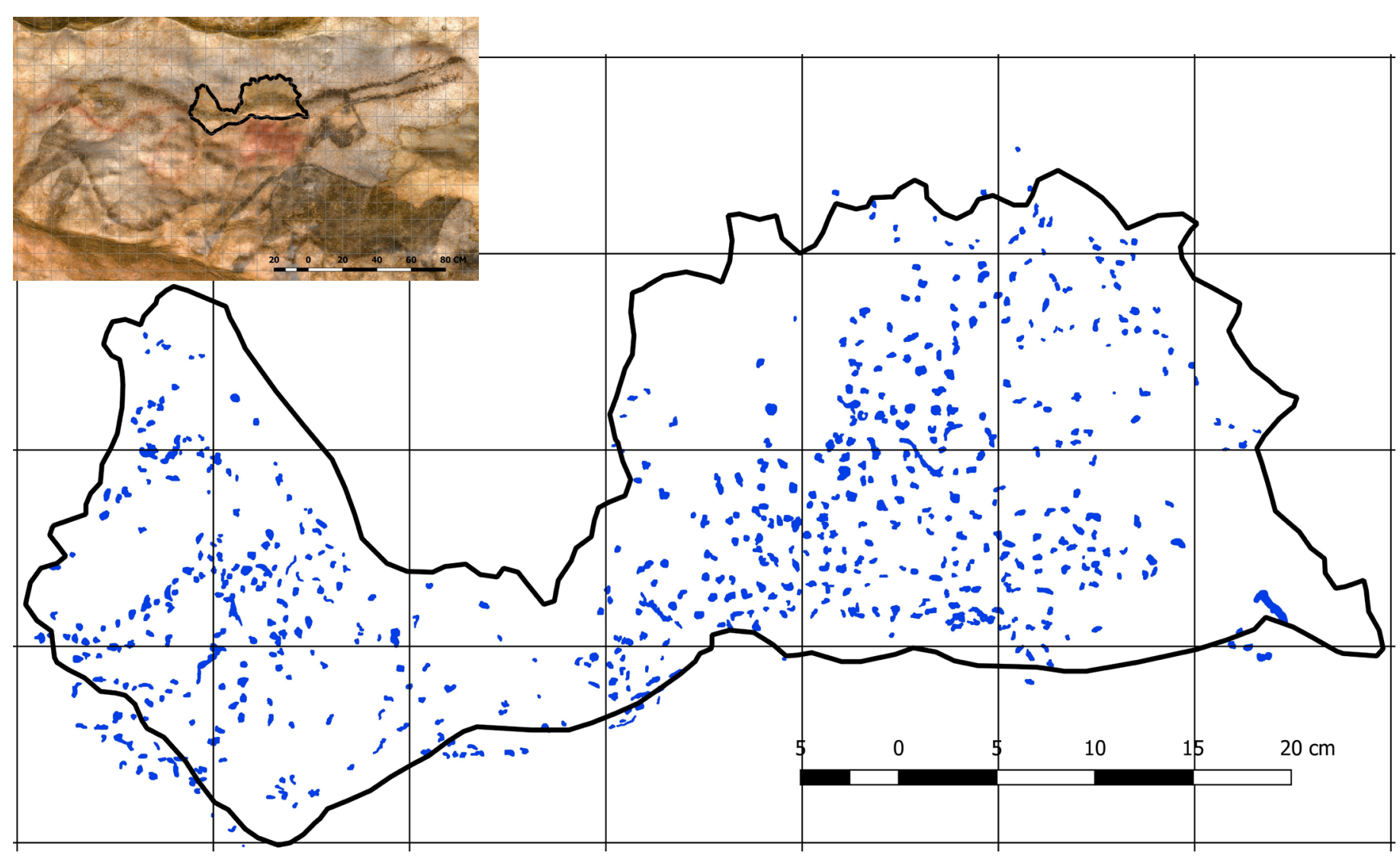

Fig. 7. Mapping of all the vermiculations detected in the STG9 area between January 2, 1980 and March 1, 2018. Inset: location of the STG9 area (back of the unicorn on the left wall of the Hall of Bulls). The total surface of the STG9 area is $1,237 \mathrm{~cm}^{2}$. 
While the number of disappeared vermiculations is too small to be interpreted, an appreciable number of shape modifications was observed from 2010, at which point a large number of vermiculations was already present on the wall. The formation of new vermiculations and shape modification of existing ones were concomitant in the years after, likely because both events are related to the mobility of the sediment on the wall.

Table 2. Vermiculation evolution in the STG9 area of the Hall of Bulls, from an undetermined date to 1980 (first line), from 1980 until 2009 (second line), and after each year up to 2018 (next lines). Reported evolutions include the formation of new vermiculations and the modification or disappearance of existing vermiculations.

\begin{tabular}{|l|c|c|c|}
\hline \multicolumn{1}{|c|}{ Date } & New & Modified & Disappeared \\
\hline $2 / 1 / 1980$ & 33 & 0 & 0 \\
\hline $10 / 13 / 2009$ & 376 & 0 & 0 \\
\hline $11 / 29 / 2010$ & 235 & 106 & 0 \\
\hline $11 / 22 / 2011$ & 15 & 18 & 0 \\
\hline $11 / 15.2012$ & 7 & 14 & 0 \\
\hline $11 / 14 / 2013$ & 6 & 26 & 0 \\
\hline $2 / 10 / 2014$ & 15 & 7 & 0 \\
\hline $4 / 6 / 2015$ & 0 & 2 & 1 \\
\hline $7 / 11 / 2016$ & 12 & 20 & 2 \\
\hline $1 / 8 / 2017$ & 14 & 21 & 12 \\
\hline $1 / 3 / 2018$ & 1 & 9 & 2 \\
\hline TOTAL & $\mathbf{7 1 4}$ & $\mathbf{2 2 3}$ & $\mathbf{1 7}$ \\
\hline
\end{tabular}

An important question for conservation purposes is the role of painting pigments in the vermiculation process. The literature revealed the possibility of complicated interactions between metallic oxides and smectites (Bailey et al., 2015). However, a close inspection of the available images of the STG9 and STG19 areas showed that vermiculations close to a painted line take the color of this line, which reinforces the idea of particle migration, but no difference in vermiculation density or shape was observed. Therefore, pigments seem to act as passive tracers in the vermiculation process. This observation has prompted us to focus on sediment behavior without considering the specific role of pigments.

The temperature and humidity of the cave walls were also monitored in Lascaux cave. Annual cycles are observed with some trends over longer periods of time. Cave walls change from dry to wet every year with some variations. From the available data, it was not possible to identify a clear correlation between these variations and 'vermiculation events'. However, monitoring were performed at rather long intervals ( $\sim 4$ times a year), which is obviously longer than the duration of 'vermiculation events'. The chemical composition of water films was not monitored.

\section{CONCLUSION}

Patterns produced through the vermiculation process are the signature of wall sediment displacement. These sediments are granular pastes containing colloidal particles that ensure material cohesion, except under specific unfavorable physicochemical conditions. Indeed, rheological experiments suggest that the cohesion of cave natural sediments can be strongly affected by the chemical composition of thin water films present on cave walls.

More specifically, we have shown that a solid-toliquid transition can occur in a natural sediment, very similar to the sediment of Lascaux, when it is soaked successively in a solution containing monovalent cations and in low-mineralized water. The sediment may then flow under very small mechanical stress. In the present article, we provide experimental values of the $\mathrm{NaCl}$ concentration and the characteristic time needed to achieve the solid-to-liquid transition, i.e., approximately $10 \mathrm{mmol} / \mathrm{L}$ and one hour, respectively. Notice that this time is very short.

This complicated behavior is typical of the smectite clay included in the sediment of Lascaux and likely of other caves in the same area, where many valuable painted caves can be found. It depends strongly on the chemical composition of thin water films on cave walls, which is poorly known. However, data available for the Hall of Bulls of Lascaux Cave suggest that this composition is highly complex, and differs greatly from well-known karst aquifers or percolation water usually found in caves. The chemical composition of such thin films, characterized by very small thickness and low flow rate, is likely related to the cave climate controlling condensation and evaporation, and to microbiology, which develops and interacts directly with these thin water films. The composition could therefore significantly vary with time, resulting in fluctuations in cation concentrations and salinity, which could trigger changes in the cohesion of sediments present at cave walls.

To date, no clear correlation has been found between the observed 'vermiculation events' (especially during the crisis of 2009-2010) and the monitored data, such as cave temperature, $\mathrm{CO}_{2}$ concentrations, and wall humidity. We believe that the causes of the vermiculation crisis that occurred in Lascaux Cave in 2009-2010 cannot be identified due to the lack of chemical data. For this reason, it seems essential to monitor the chemical composition of water films in painted caves. Chemical analyses must include the dosage of organic ions and an investigation of the factors that influence the solubility of calcium carbonate. Comparisons between Lascaux and nonanthropized caves, such as Maillol Cave, would certainly provide a large amount of information, as well as laboratory experiments to further interpret field observations.

It is clear that the vermiculation process involves complex and strongly coupled physical mechanisms. An understanding of these different phenomena and their interactions is necessary to improve the management of painted caves. In Lascaux Cave, the geographic information system that we developed for the walls of the Hall of Bulls (with a special module for the study of vermiculations) will help to identify potential correlations between displacement of vermiculations, humidification phases of the walls, temperature evolution monitored by the large number of sensors located in the cave, and chemical data. 
This study has been dedicated to Lascaux Cave, but it should be possible to extend our approach to other caves. Indeed, a significant amount of colloidal particles are present in cave sediment, which control its cohesion. For colloids other than smectites (e.g., other clays or metallic oxides), different behaviors are expected. Determining the nature of the colloidal fraction should make it possible to assess this behavior.

\section{ACKNOWLEDGMENTS}

This work was supported by the French Ministry of Culture, Direction des Affaires Culturelles de Nouvelle-Aquitaine; Marché public de services $\mathrm{n}^{\circ}$ 2015.72.020. We thank J.-C. Portais and S. Géraud (DRAC Nouvelle-Aquitaine), and S. Konik (CNP) for their help, A. Aubertin, L. Auffray, J. Amarni, R. Pidoux and C. Manquest (FAST) for technical support, D. Calmels, C. Quantin, G. Monvoisin, O. Dufaure and S. Miska (GEOPS) for chemical analyses and geological characterization of our samples. We also thank Y. Moënne-Loccoz (EML) and M. Rossi (IJLRA) for stimulating discussions.

Author statement: PYJ supervised the study and discussed all aspects. EW developed the GIS tool and photogrammetric measurements for mapping vermiculations. PF performed the rheological measurements, and analyzed the results with the participation of $B G, F D$, and JM. FD wrote the paper with the inputs of all authors.

\section{REFERENCES}

Abend, S., Lagaly, G., 2000. Sol-gel transitions of sodium montmorillonite dispersions. Applied Clay Science, 16, 201-227.

https://doi.org/10.1016/S0169-1317(99)00040-X

Addesso, R., Bellino, A., D’Angeli, I.M., De Waele, J., Miller, A.Z., Carbone, C., Baldantoni, D., 2019. Vermiculations from karst caves: The case of PertosaAuletta system (Italy). Catena, 182, 104178.

https://doi.org/10.1016/j.catena.2019.104178

Alonso, A., Pommier, T., Kaufmann, B., Chapulliot, D., Doré, J., Douady, C.J., Dubost, A, Moënne-Loccoz, Y., 2019. Anthropization level of Lascaux Cave microbiome shown by regional-scale comparisons of pristine and anthropized caves. Molecular Ecology, 28, 3383-3394. https://doi.org/10.1111/mec.15144

Bailey, L., Lekkerkerker, H.N.W., Maitland, G.C., 2015. Smectite clay - inorganic nanoparticle mixed suspensions: phase behaviour and rheology. Soft Matter, 11, 222-236. https://doi.org/10.1039/C4SM01717J

Barton, H.A., Northup, D.E., 2007. Geomicrobiology in cave environments: past, current and future perspectives. Journal of Cave and Karst Studies, 69, 163-178.

Bini, A., Cavalli Gori, M., Gori, S., 1978. A critical review of hypotheses on the origin of vermiculations. International Journal of Speleology, 10(1), 11-33. https://digitalcommons.usf.edu/ijs/vol10/iss1/2

Birgersson, M., Hedström, M., Karnland, O., 2011. Sol formation ability of $\mathrm{Ca} / \mathrm{Na}$-montmorillonite at low ionic strength. Physics and Chemistry of the Earth, Parts
A/B/C, 36, 1572-1579.

https://doi.org/10.1016/j.pce.2011.07.017

Bojar, A.-V., Guja, O., Stefănescu, D., 2015. Vermiculation patterns in Coiba Mare Cave, Bihor Mountains, Romania. Quaternary International, 357, 212-219.

https://doi.org/10.1016/j.quaint.2014.07.028

Boston, P., Curnett, J., Gomez, E., Schubert, K., Strader, B., 2009. Patterned growth in extreme environments. In proceedings of the Third IEEE International Conference on Space Mission Challenges for Information Technology, Pasadena, 221-226.

https://doi.org/10.1109/SMC-IT.2009.34

Clottes, J., 1981. Circonscription de Midi-Pyrénées. Gallia Préhistoire, 24, 525-570.

Coussot, P., Ancey, C., 1999. Rheophysical classification of concentrated suspensions and granular pastes. Physical Review E, 59, 4445-4457.

https://doi.org/10.1103/PhysRevE.59.4445

de Freitas, C.R., Schmekal, A., 2006. Studies of condensation/evaporation processes in the Glowworm Cave, New Zeland. International Journal of Speleology, 35(2), 75-81.

https://digitalcommons.usf.edu/ijs/vol35/iss2/3

Faucher, B., Lauriol, B., 2016. Les vermiculations de la grotte Wilson (Lac la Pêche, Québec, Canada). Contexte morphoclimatique, analyses sédimentologiques et distribution spatiale. Géomorphologie: relief, processus, environnement, 22, 96-103.

https://doi.org/10.4000/geomorphologie. 11280

Ford, D.C., Williams, P.W., 2007. Karst hydrogeology and geomorphology. Wiley, $562 \mathrm{p}$.

https://doi.org/10.1002/9781118684986

Freydier, P., Martin, J., Guerrier, B., Jeannin, P.Y., Doumenc, F., 2019. Rheology of cave sediments: application to vermiculation. Rheologica Acta, 58, 675685. https://doi.org/10.1007/s00397-019-01167-7

Guerrier, B., Doumenc, F., Roux, A., Mergui, S., Jeannin, P.Y., 2019. Climatology in shallow caves with negligible ventilation: heat and mass transfer. International Journal of Thermal Sciences, 146, 106066. https://doi.org/10.1016/j.ijthermalsci.2019.106066

Hedström, M., Hansen, E.E., Nilsson, U., 2016. Montmorillonite phase behaviour. Relevance for buffer erosion in dilute groundwater. Technical Report TR15-07. SKB.

Hœrlé, S., 2012. Etat des connaissances et étude minérale des vermiculations de la grotte de Lascaux. Volet 1 Etat des connaissances sur les vermiculations. Reports on "Vermiculations in Lascaux cave", Unpublished Report, French Ministry of Culture.

Hœrlé, S., Konik, S., Chalmin, É., 2011. Les vermiculations de la grotte de Lascaux: identification de sources de matériaux mobilisables par microanalyses physicochimiques. Karstologia, 58, 29-40. https://doi.org/10.3406/karst.2011.2703

Jones, D.S., Lyon, E.H., Macalady, J.L., 2008. Geomicrobiology of biovermiculations from the Frasassi Cave system, Italy. Journal of Caves and Karst Studies, 70, 78-93.

Jurado, V., Gonzalez-Pimentel, J.L., Miller, A.Z., Hermosin, B., D’Angeli, I.M., Tognini, P., De Waele, J., Saiz-Jimenez, C., 2020. Microbial communities in vermiculations deposits from an alpine cave. Frontiers in Earth Science, 8, 586248. https://doi.org/10.3389/feart.2020.586248

Karnland, O., Birgersson, M., Hedström, M., 2011. Selectivity coefficient for $\mathrm{Ca} / \mathrm{Na}$ ion exchange in highly compacted bentonite. Physics and Chemistry of the 
Earth, Parts A/B/C, 36, 1554-1558.

https://doi.org/10.1016/j.pce.2011.07.023

Konik, S., Géraud-Van Solinge, S., 2012. Suivi des vermiculations de la Salle des Taureaux de la grotte de Lascaux. Résultats de l'année 2011. Reports on "Vermiculations in Lascaux cave", Unpublished Report, French Ministry of Culture.

Konik, S., Lafon-Pham, D., Riss, J., Aujoulat, N., Ferrier, C., Kervazo, B., Plassard, F., Reiche, I., 2014. Etude des vermiculations par caractérisations morphologique, chromatique et chimique. L'exemple des grottes de Rouffignac et de Font-de-Gaume (Dordogne, France). Paleo, Special Issue, 311-321.

Lopez, B., 2009. Les processus de transfert d'eau et de dioxyde de carbone dans l'épikarst. Unpublished MS Thesis, University of Bordeaux 1, 399 p.

Parenzan, P., 1961. Sulle formazioni argillo-limose dette vermicolari. In Rassegna Speleologica Italiana: Memorie 5, Tomo II, 120-125.

Plummer, L.N., Wigley, T.M.L, 1976. The dissolution of calcite in $\mathrm{CO}_{2}$-saturated solutions at $25^{\circ} \mathrm{C}$ and 1 atmosphere total pressure. Geochimica et Cosmochimica Acta, 40, 191-202. https://doi.org/10.1016/0016-7037(76)90176-9

Reddy, K.J., Lindsay, W.L., Workman, S.M., Drever, J.I., 1990. Measurement of calcite ion activity products in soils. Soil Science Society of America Journal, 54, 67-71. https://doi.org/10.2136/sssaj1990.03615995005400010010x Segad, M., Jönsson, B., Åkesson, T., Cabane, B., 2010. $\mathrm{Ca} / \mathrm{Na}$ montmorillonite: structure, forces and swelling properties. Langmuir, 26, 5782-5790. https://doi.org/10.1021/la9036293

White, W., 2015. Chemistry and karst. Acta Carsologica, 44, 349-362. https://doi.org/10.3986/ac.v44i3.1896 
